\title{
Histological Changes in the Articular Eminence and Mandibular Fossa During Growth of the Rhesus Monkey (Macaca mulatta)
}

\author{
ROBERT J. HINTON AND DAVID S. CARLSON \\ Department of Anatomy and Center for Human Growth and Development, \\ University of Michigan, Ann Arbor, Michigan 48109
}

\begin{abstract}
Unlike the mandibular condyle, the temporal component of the temporomandibular joint (TMJ) has been the object of relatively few investigations concerning its growth and remodeling. This report provides qualitative and quantitative documentation of microanatomical changes in the mandibular fossa and articular eminence during growth of the rhesus monkey (Macaca mulatta). The thickness of the fibrous articular tissue and the presence of cartilage cells in its deeper layers were examined histologically in 43 rhesus monkeys at five maturational levels (neonate, infant, juvenile, adolescent, and young adult). Absolute thickness of the articular tissue increased with maturational level in all areas studied, with the increase somewhat more pronounced on the posterior slope and crest of the articular eminence than in the roof of the mandibular fossa. Relative to condylar size, an increase in articularlayer thickness characterized the first three maturational levels, and was followed by a decrease during adolescent and young-adult stages. Articular tissue in the fossa roof constituted a steadily decreasing fraction of the total articular-tissue thickness with age, while relative thickness of the tissue on the posterior slope and crest of the eminence increased with age. These results parallel those obtained for the mandibular condyle, and they are best interpreted to indicate that forces delivered to the joint become directed more anteriorly with age. The overall pattern of topographical variation in articulartissue thickness and cartilage-cell distribution suggests that greater loading of the lateral aspect of the TMJ, postulated in the human TMJ by various workers, may not be as pronounced in the monkey.
\end{abstract}

In recent years, a number of studies have investigated the role of the temporomandibular joint in craniofacial growth and adaptation. With few exceptions, studies of the temporomandibular joint have concentrated on changes in the mandibular condyle. This focus is understandable in terms of both the contribution of the condylar cartilage to normal facial growth and its potential for compensatory growth in response to altered occlusion. The temporal component of the temporomandibular joint, which is thought to possess a much more limited adaptive potential, has been much less studied. However, there are indications that the temporal component of the temporomandibular joint, as with the condyle, may undergo morphological change in response to occlusal perturbations and altered jaw function. In adult humans, changes in the contours of the articular eminence have been correlated with in- creasing dental attrition or loss of posterior teeth (Moffett et al., 1964; Seward, 1976; Granados, 1979; Hinton, 1981); and it is possible that changes during growth are also influenced by orofunctional stimuli.

The rhesus monkey (Macaca mulatta) has been utilized extensively as an animal model in many experimental studies of facial growth because of similarities in craniofacial form with humans. However, even in this species information concerning growth of the mandibular fossa and articular eminence is sparse. Aside from comments incidental to experimental investigations (e.g., Hiniker and Ramfjord, 1966; Stöckli and Willert, 1971; McNamara, 1972), detailed descriptions of the normal microanatomy and post-

\footnotetext{
Address reprint requests to Dr. Robert J. Hinton, Department of Anatomy, Medical Science II, The University of Michigan, Ann Arbor, MI 48109.

Received May 3, 1982. Accepted August 2, 1982
} 
natal growth of the temporal-component joint structures in Macaca mulatta are limited to unpublished master's theses (Zielinski, 1965; Zimmermann, 1971). Moreover, with the partial exception of that of Zimmermann (1971), all accounts are essentially qualitative.

This investigation was undertaken to provide a quantitative description of the normal microanatomy and growth of the tissues of the mandibular fossa and articular eminence from the neonate through the young adult in the rhesus monkey (Macaca mulatta). In addition to their potential interest in terms of connective-tissue biology, these data should constitute a baseline against which changes brought about by experimental intervention can be assessed.

\section{NORMAL ANATOMY OF THE MANDIBULAR FOSSA AND ARTICULAR EMINENCE}

The temporal component of the temporomandibular joint consists of a mandibular (glenoid) fossa, bordered anteriorly by the articular eminence and posteriorly by the postglenoid spine (Fig. 1). In overall appearance, the joint structures in the rhesus monkey bear a marked resemblance to those in hu- mans. However, the postglenoid spine is much more strongly developed in the monkey than in humans and is a prominent feature in lateral and central sagittal sections through the joint (Carlson et al., 1980). Also, the slight concavity of the mandibular fossa in the neonate becomes gradually flatter with age in the rhesus monkey, in contrast to a continued deepening in humans. Zimmermann (1971) attributed the progressive flattening of the fossa in the monkey to a higher rate of bone deposition in the fossa than on the surface of the articular eminence, with the result that an eminence is often no longer recognizable in medial sections in adult animals.

As with the mandibular condyle, the surfaces of the temporal component of the temporomandibular joint are covered with a layer of dense, fibroelastic connective tissue whose collagen fibers are oriented parallel to the surface. This layer, known as the articular layer or zone, is largely avascular and varies in thickness along the joint contours. Radioautographic studies in the rat (Folke and Stallard, 1967) and in monkeys (Joondeph, 1972) indicate that the widely scat-

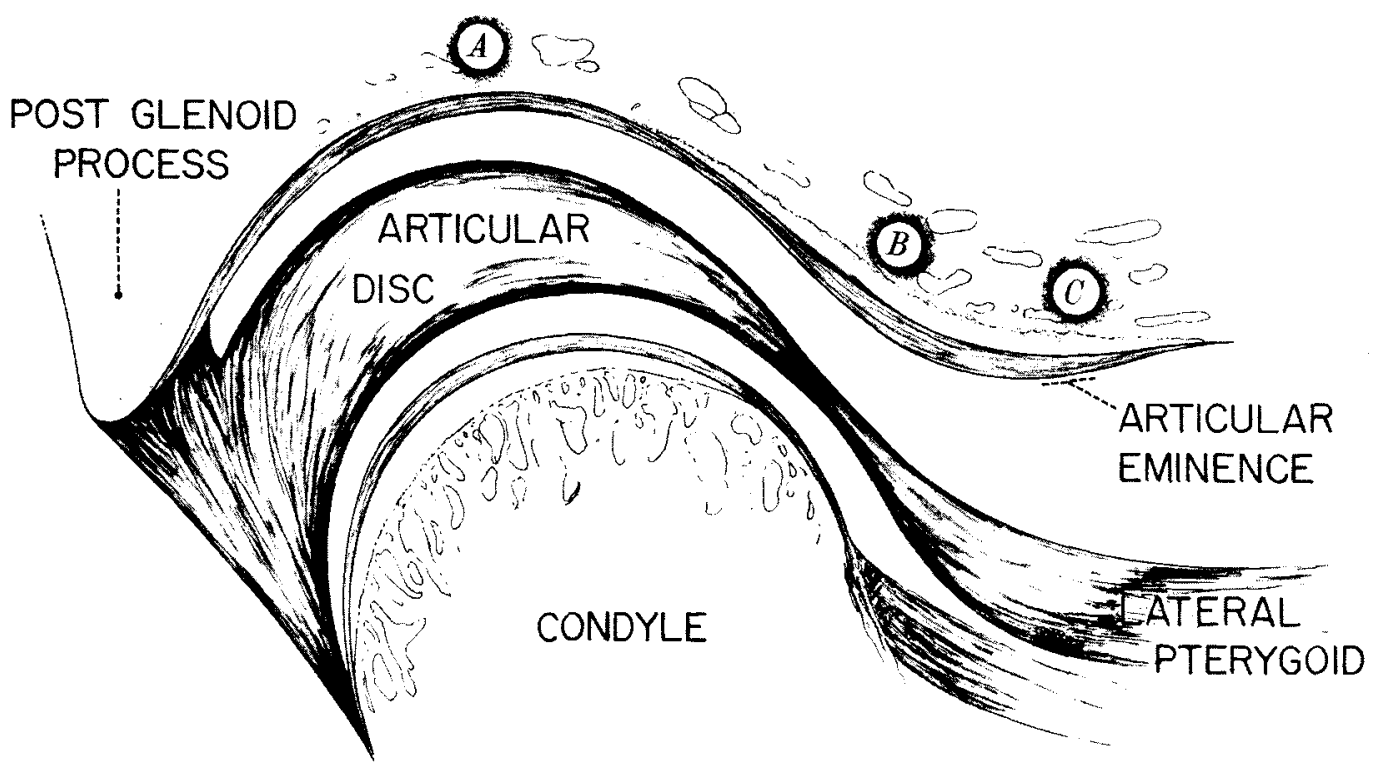

Fig. 1. Schematic overview of temporomandibular joint structures. $\mathrm{A}, \mathrm{B}$, and $\mathrm{C}$ designate locations along the joint contour at which measurements were taken. A)
Roof of mandibular fossa; B,C) Posterior slope and crest, respectively, of articular eminence. 
tered fibroblasts in the articular layer and the undifferentiated cells at its deep boundary act primarily to replenish and maintain the articular tissue against erosion due to function, and do not participate in the growth process.

Deep to the articular layer, the temporal component lacks layers of proliferative and chondroblastic cells strictly analogous to those observed in the condyle of growing animals. Instead, in the mandibular fossa at all ages and on the articular eminence in very young animals, the articular layer is bounded on its deep aspect by the bony joint surface. In the fossa, the bone bordering the articular layer is usually composed of slightly remodeled compact bone, whereas on the posterior slope and crest of the eminence the bone is characterized by a more heavily remodeled cortex. Secondary osteons are observed frequently in older animals in this region. Several workers (Zimmermann, 1971; Stöckli and Willert, 1971; McNamara, 1972) have described a narrow zone of "cartilage" intervening deep to the fibrous articular layer on the crest and posterior slope of the articular eminence in juvenile to young-adult animals. This zone, which usually contains rounded cells resembling chondrocytes, is separated from the articular layer by what appears to be a zone of undifferentiated or mesenchymal cells. The subsequent presence in adolescent or young-adult animals of "hyper. trophying chondrocytes" (Zimmerman, 1971; McNamara, 1972) in the deepest layers adjacent to the bone has led to the characterization of a "three-layer structure" on the eminence resembling that which occurs in the condyle (Stöckli and Willert, 1971; Zimmermann, 1971). However, the timing of occurrence and topographical distribution of this "cartilage" layer is unclear, as is its significance and/or contribution to the growth of the eminence.

Finally, several lines of evidence suggest that the articular surface of the temporomandibular joint may undergo differential loading during function, with somewhat greater force dissipation on the lateral aspect of the joint than on the medial aspect (Oberg et al., 1971; Hansson et al., 1977; Hansson and Nordstrom, 1977; Kopp, 1978; Hylander, 1979a). This idea is based primarily on indirect evidence and is largely unsubstantiated, although it is supported by the existence of differing patterns of remodeling on lateral and medial joint surfaces in older human adults (Moffett et al., 1964).

\section{MATERIALS AND METHODS}

The sample and methods used in this study are the same as those described previously in a study of the normal growth of the mandibular condyle by Carlson and co-workers (1978). Forty-three rhesus monkeys (Macaca mulatta) from the primate colony of the Center for Human Growth and Development, University of Michigan, were divided into five maturational levels for analysis. Animals from the first age group, neonate $(\mathrm{n}=$ 3 , were obtained immediately postpartum. The infant monkeys $(\mathrm{n}=6)$ had a complete deciduous dentition at the time of death, and ranged in known age from 6 to 12 months. The remaining three groups were delimited on the basis of dentitional development (Hurme and Van Wagenen, 1953, 1961). Juveniles $(\mathbf{n}=14$ ) were characterized by a complete deciduous dentition and had their first permanent molars in full occlusion. These monkeys ranged in age from 18 to 30 months. The adolescent animals $(n=8)$ had a full permanent dentition, with the exception of unerupted third molars, and were 4 to 5 years of age. The animals in the young adult $(\mathrm{n}=$ 12) group possessed complete permanent dentitions, including fully erupted third molars and were 7 or more years of age.

A lateral radiographic cephalogram of each monkey was obtained immediately prior to death. All radiographs were taken, using a cephalostat especially designed for the laboratory monkey, at a distance of $155 \mathrm{~cm}$ (Elgoyhen et al., 1972; McNamara, 1972).

Following perfusion with saline and phosphate-buffered formalin, the right temporomandibular joint and its surrounding tissues were removed and placed in neutral buffered formalin. The tissue block was washed and decalcified in formic acid, embedded in either celloidin or paraffin, and sectioned serially in the sagittal plane at $10-20 \mu \mathrm{m}$. All sections were then stained with hemotoxylin and eosin. Histological sections were magnified $(\times 10)$ and microprojected $(\times 4.5)$ onto a flat surface from a distance of 9 feet. Tracings were made of the temporomandibular joint structures, emphasizing the articular tissue layer and the "cartilage" layer where present.

\section{Measurements}

Maximum length of the mandibular condyle was measured perpendicular to the posterior border of the ramus on the lateral cephalograms. Thickness of the articular tis- 
sue layer was measured perpendicular to the articular surface at three locations on the tracings: roof of the mandibular fossa; halfway along the posterior slope of the articular eminence; and crest of the articular eminence (Fig. 2). In order to account for variation in thickness due to general body size, thickness values were divided by condylar length (Carlson et al., 1978). In addition, the presence and location along the sagittal contour of cartilage cells were noted in qualitative terms. When cartilage cells were present as a layer, a thickness measurement was obtained for the total layer (articular tissue and cartilage), in addition to the measurement of articular-layer thickness.

Where possible, observations were recorded from sections taken serially from lateral to medial aspects of the joint surface. Using morphological criteria (e.g., presence and/or prominence of the postglenoid spine, extent of condylar neck visible, attachment of lateral pterygoid muscle) and the order of sectioning, the histological sections were characterized as medial, central, or lateral.
Since the plane of sectioning can exert an influence on thickness measurements, great care was taken to position tissue blocks so as to minimize this potential source of error. Despite these precautions by an experienced technician, some error undoubtedly was introduced. However, we feel that its influence on the results is likely to be small. In any event, the relative magnitudes of regional thickness measurements, which are an important focus of this study, were quite consistent from one animal to another. Means and standard deviations were determined to evaluate variation within each maturational level. One-way analysis of variance and nonsimultaneous two-sample F-tests were computed to determine the significance of intergroup differences.

\section{RESULTS \\ Articular tissue}

The absolute thickness of the articular layer showed a progressive increase between maturational levels for all three regions

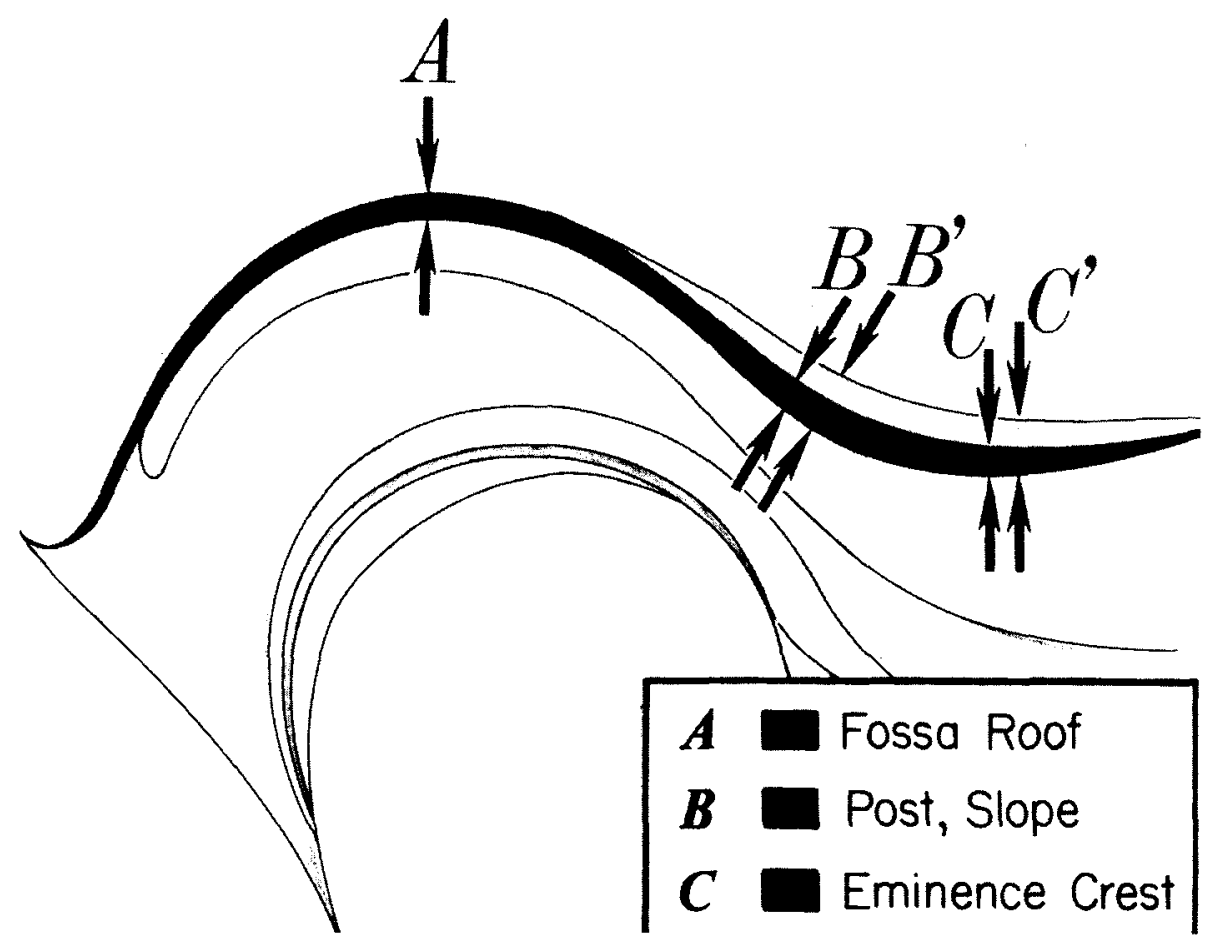

Fig. 2. Measurements of connective-tissue thickness. A, B, C) Fibrous articular-tissue thickness in roof of mandibular fossa and on posterior slope and crest of articular eminence, respectively. $\mathrm{B}$ ', $\left.\mathrm{C}^{\prime}\right)$ Total softtissue thickness including cartilage layer at posterior slope and crest of articular eminence, respectively. 
studied (Fig. 3, Table 1). The trend toward increasing thickness appeared more gradual in the fossa roof than on the posterior slope of the articular eminence and eminence crest. Within each maturational level, the articular layer decreased in absolute thickness from medial to lateral aspects of the joint surface. However, relative to the size of the condyle, the tissue in the fossa roof showed a trend for a gradual decrease in relative thickness with increasing maturational level, especially in central and lateral sections (Fig. 4).

By contrast, relative articular-tissue thickness on the posterior slope and crest of the eminence increased through the juvenile period, followed by a relative decrease in thickness during adolescent and young-adult ages. The most significant $(\mathrm{P} \leqslant 0.5)$ changes occurred between the juveniles and those maturational levels immediately preceding or following them (Table 2). Inclusion of the thickness of the cartilage layer, present in some animals, to yield an overall noncalcified tissue thickness resulted in virtually identical patterns of change (hatched areas in Figs. 3 and 4 represent the increases resulting from the inclusion of cartilage-layer thicknesses, where present).

Evaluation of the relative thickness (percentage of total articular-tissue thickness) of each of the three regions by age group further demonstrated general patterns of change during growth. Articular-tissue thickness in the fossa roof, which was only slightly less than that on the eminence in neonates, underwent a steady reduction over subsequent maturational levels, while relative thickness of the tissue on the posterior slope and crest of the eminence increased (Fig. 5). Thus, in sections from the central part of the joint, relative thickness in the fossa roof decreased from $34 \%$ in neonates to $18 \%$ in adults, while eminence-crest thickness increased from $33 \%$ in neonates to $43 \%$ in adults. The articular tissue became rela. tively thicker with age in the medial part of the joint, although this tendency was less pronounced on the eminence crest than it was in the fossa roof (Fig. 6).

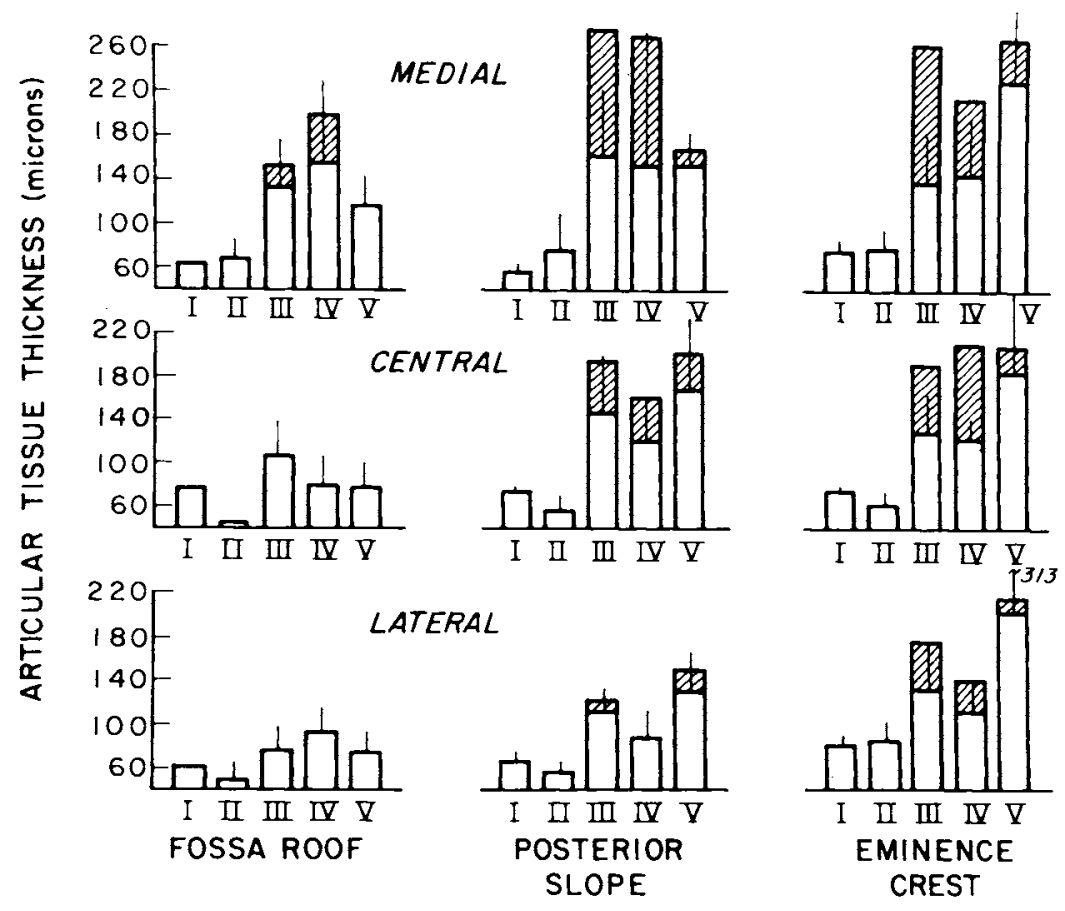

Fig. 3. Mean articular-tissue thickness as a function of maturational level $(\mathrm{I}-\mathrm{V})$ in medial, central, and lateral parts of the joint. Unshaded bars represent means of fibrous articular-tissue layer; height of bars including cross-hatched portions represents means when cartilage layer (if present) is included. 


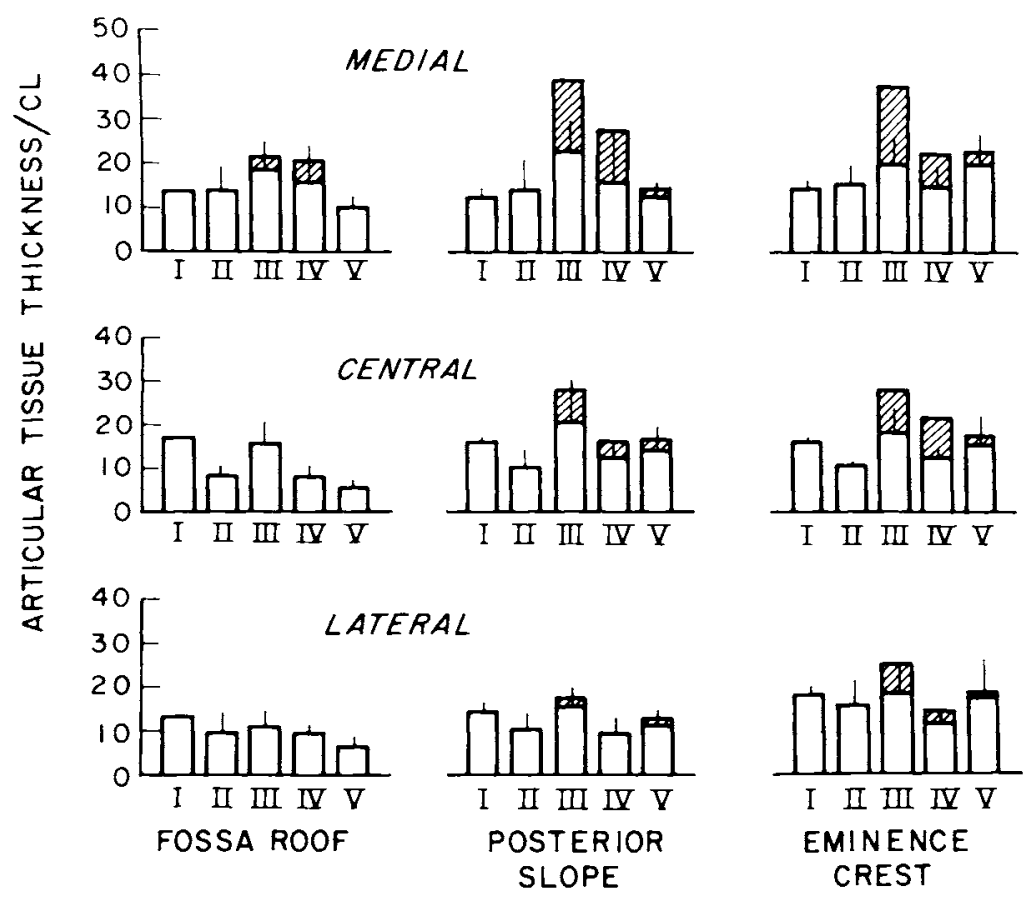

Fig. 4. Mean articular-tissue thickness divided by shaded and cross-hatched portions represent same meacondylar length as a function of maturational level (I-V) surements as in Figure 3. in medial, central, and lateral parts of the joint. Un-

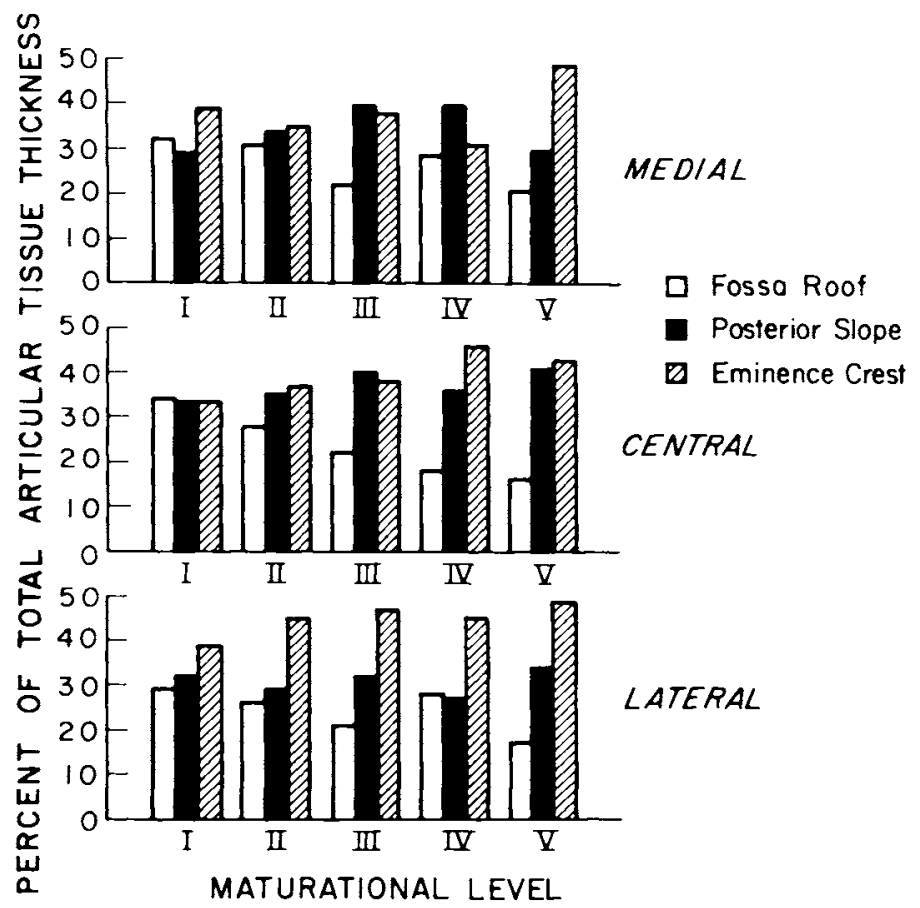

Fig. 5. Percent of total articular-tissue thickness as a function of maturational level: comparison of fossa roof, posterior slope, and crest of eminence. Percentages represent the relative proportions of the total articular- tissue thickness along given sagittal contours (e.g., cen tral) which lie in the fossa roof, posterior slope, or emin ence crest. 


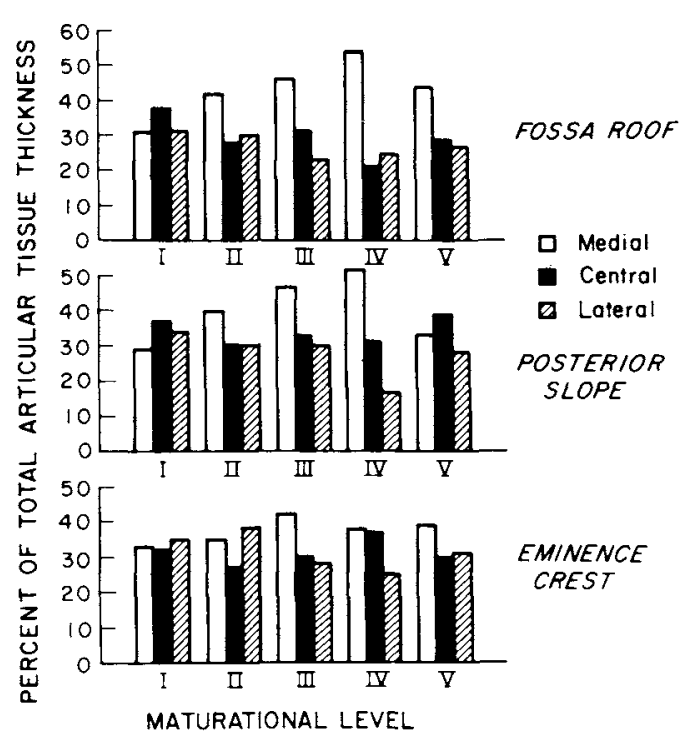

Fig. 6. Percent of total articular-tissue thickness as a function of maturational level: comparison of medial, central, and lateral regions.
Occurrence and distribution of cartilage cells

The temporal component of the joint in neonates exhibited a solid layer of lamellar bone directly underlying the fibrous articular layer (Fig. 7). Rounded cells resembling chondrocytes were first noted at the deep surface of the articular layer in infant monkeys, occurring in five of six animals. They were confined to the crest and posterior slope of the eminence, but were spaced relatively far apart and appeared to be encased in a bony matrix (Fig. 8). This tissue most likely represents a form of rapidly growing, newly deposited bone (perhaps chondroid bone I in Beresford's (1981) nomenclature) and, except for the rounded appearance of the cells them. selves, does not resemble the tissue observed at later maturational levels. In juvenile and adolescent animals, the cartilage cells were more obvious and numerous, and in many cases formed a layer of uneven thickness separating the parallel-fibered articular tissue from the cortical bone of the eminence (Fig. 9). A thin layer of small, flattened cells resembling the undifferentiated or prolifera-

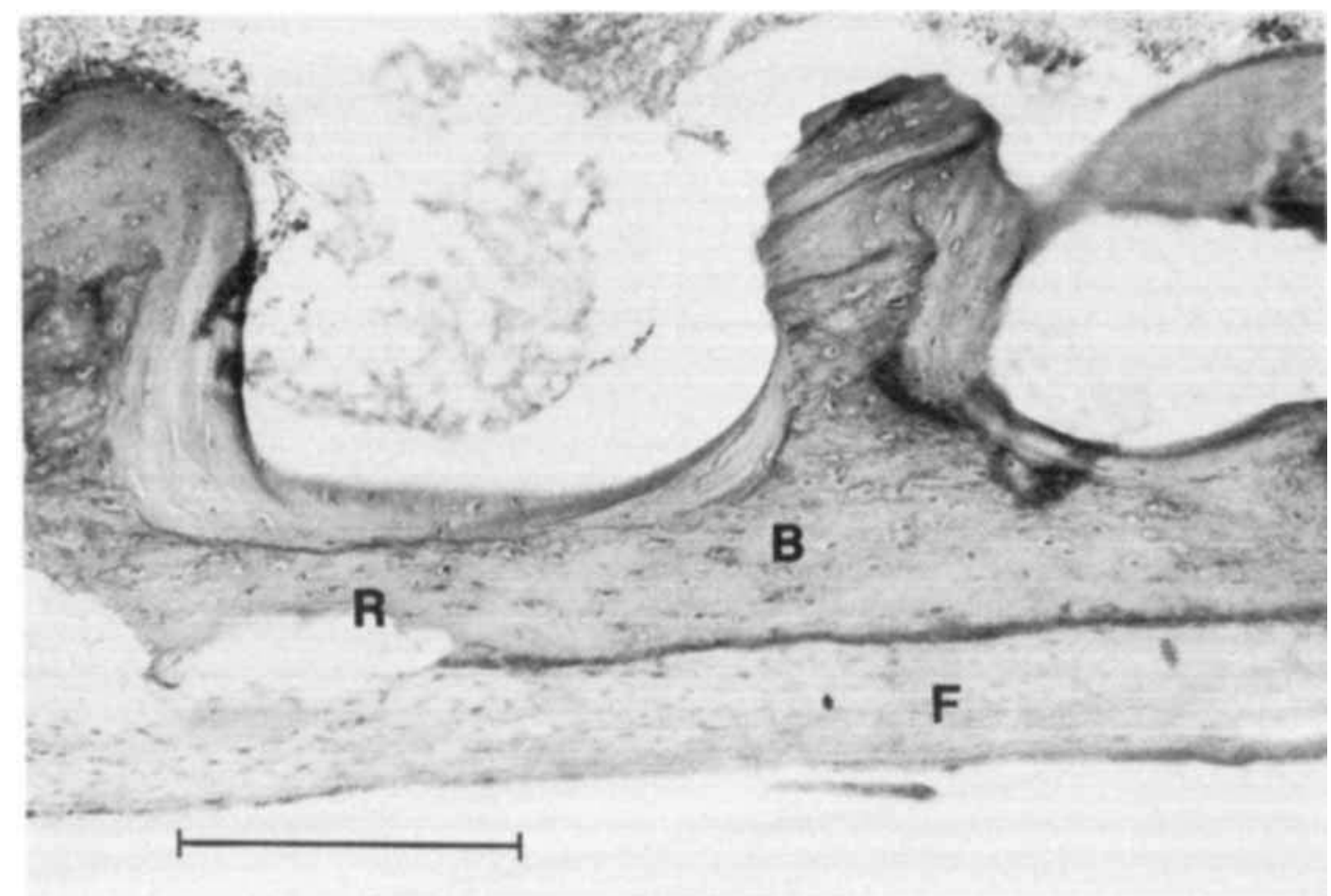

Fig. 7. Articular eminence in a neonate monkey. $\mathrm{H}$ and $\mathrm{E}$. Scale represents $200 \mu \mathrm{m}$. Location is in general vicinity of crest of articular eminence, although no real convexity is present at this maturational level. $\mathrm{F}=$ fibrous articular tissue; $\mathrm{B}=$ lamellar bone of temporal articular surface; $\mathrm{R}=$ area of bony resorption. Note that no cartilage celis are present. 


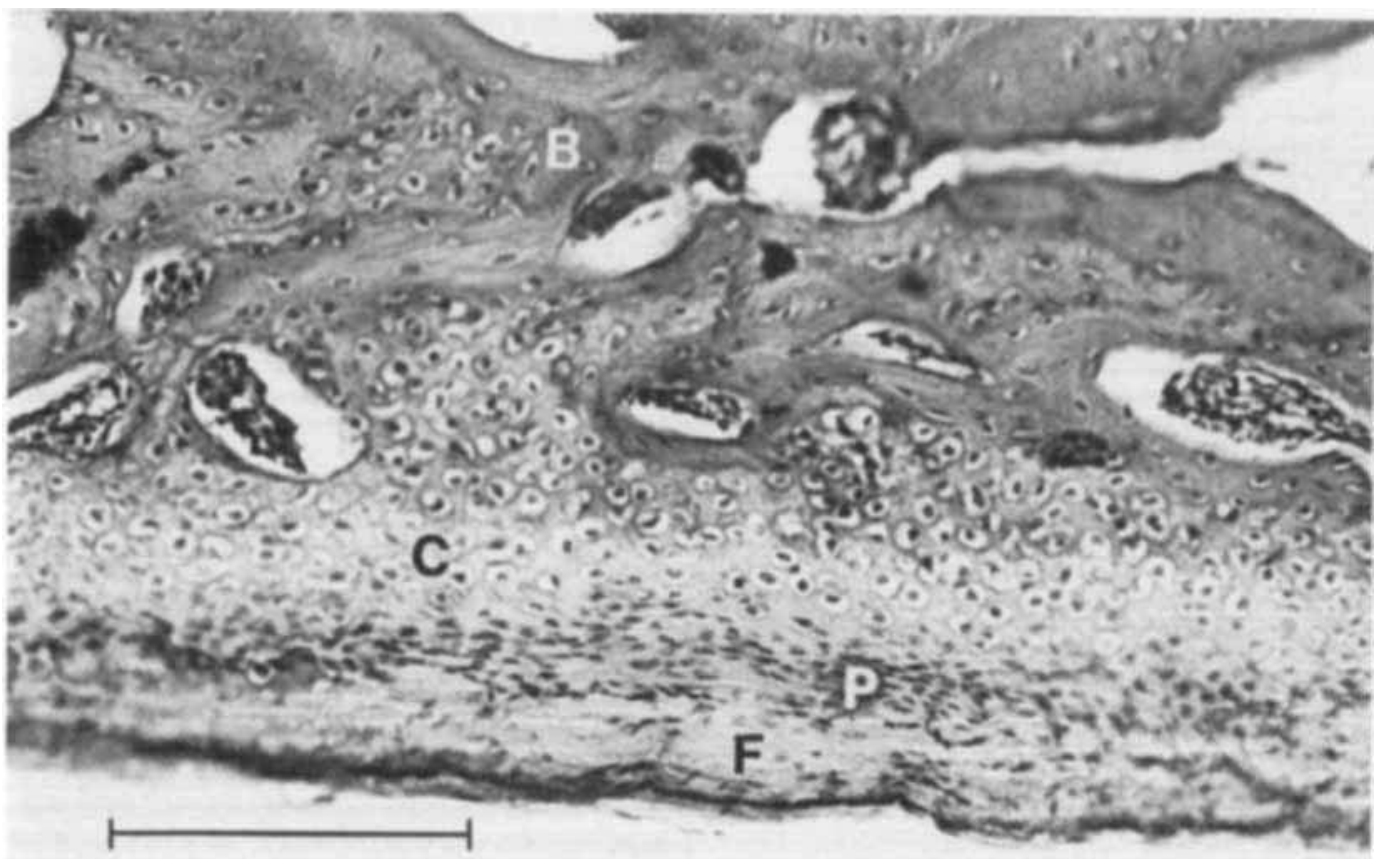

Fig. 8. Crest of articular eminence in an infant monkey. $\mathrm{H}$ and $\mathrm{E}$. Scale represents $200 \mu \mathrm{m} . \mathrm{F}=$ fibrous

articular tissue; $\mathrm{B}=$ bone of articular eminence; $\mathrm{P}=$ proliferative layer; $\mathrm{C}=$ chondroid tissue.

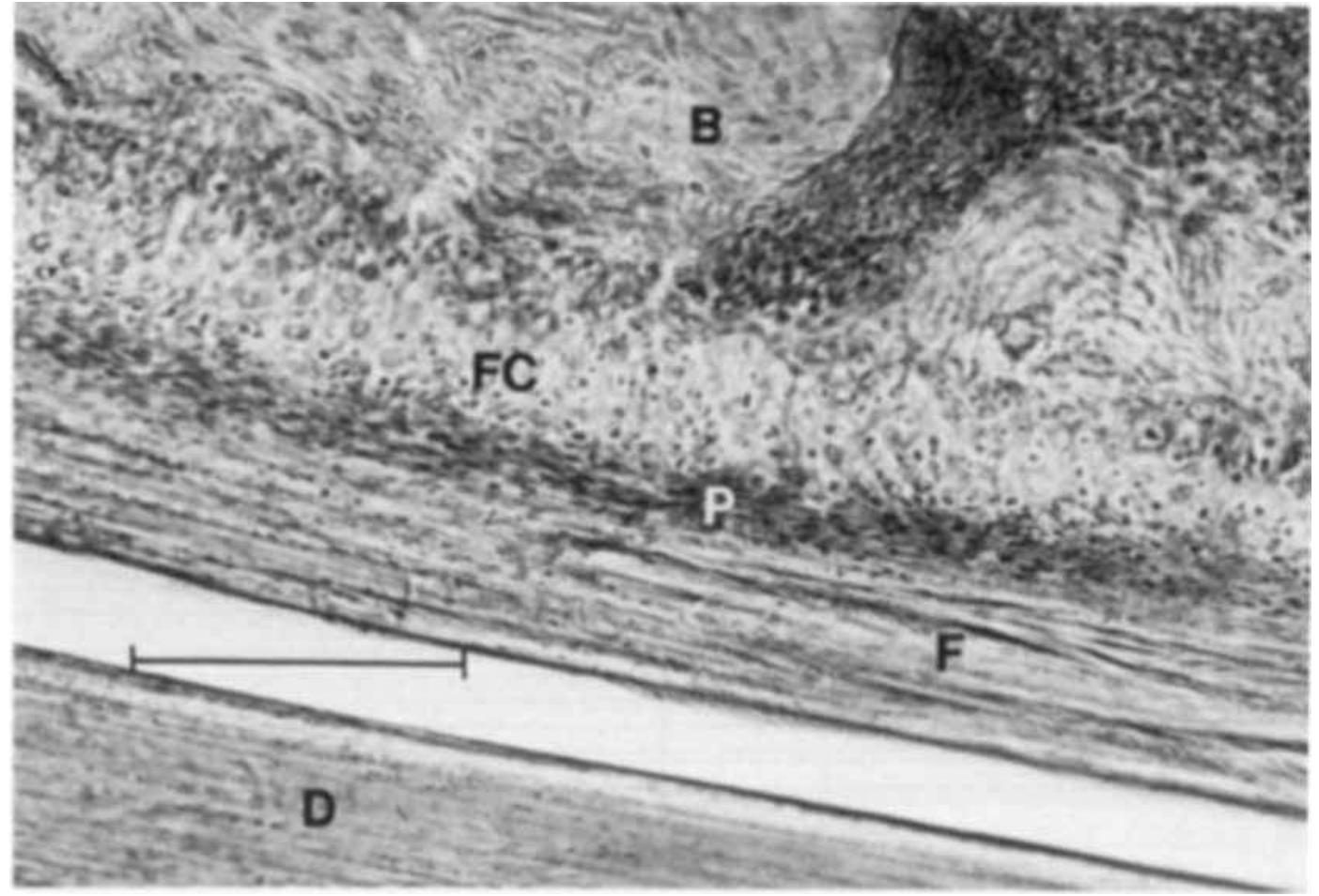

Fig. 9. Crest of articular eminence in a juvenile monkey. $\mathrm{H}$ and $\mathrm{E}$. Scale represents $200 \mu \mathrm{m}$. Note thin but distinct layer of mesenchymal cells, with chondrocytes in a fibrous matrix beneath. $F=$ fibrous articular tissue;
$\mathrm{D}=\operatorname{articular}$ disk $\mathrm{P}=$ proliferative layer $\mathrm{FC}=$ chon drocytes in fibrous matrix; $\mathrm{B}=$ bone of articular eminence. 
tive layer of the condylar cartilage was interposed between the articular tissue and the cartilage cells deep to it. In a number of cases, thin strands or fibers could be noted amidst the cartilage cells, running in a direction roughly perpendicular to the cortical bone surface (Fig. 10). In other instances, the cartilagelike cells appeared to be encased in a matrix which stained like the condylar cartilage, but less intensely. Cartilage cells were noted in 12 of 14 juveniles and six of eight adolescents. In serial sections, cartilage cells were apparent from lateral to medial across the crest of the eminence in most animals, but there was a tendency for the cartilage layer to extend backward along the posterior slope of the eminence in central and medial sections. Cartilage cells were seldom noted on the posterior slope in lateral sections, making the distribution resemble something of a "spiral," beginning in most animals on the crest of the eminence crest laterally and gradually becoming more posterior in distribution as one moves progressively more medially (note hatched areas in Figs. 3 and 4).
However, in a number of cases, the presence of cartilage cells was more pronounced medially than laterally, with a few animals lacking a cartilage layer in lateral sections. Cartilage cells were not seen in neonates. In young adults, a layer of cartilage cells between bone and articular tissue was still observed in some animals, but it was more variable in occurrence and extent. In addition, cartilage cells had begun to appear singly in the parallel-fibered articular-tissue layer and occasionally in clumps in its deeper portions, a finding not encountered in younger animals.

\section{DISCUSSION}

The data reported here are in general agreement with the more limited measurements offered by Zimmermann (1971). Zimmermann's study included animals ranging in age from juveniles to fully adult, but did not include neonates or infants as this study did. According to her results, the thickness of the articular tissue in the mandibular fossa of juvenile monkeys (aged 18-24 months) was

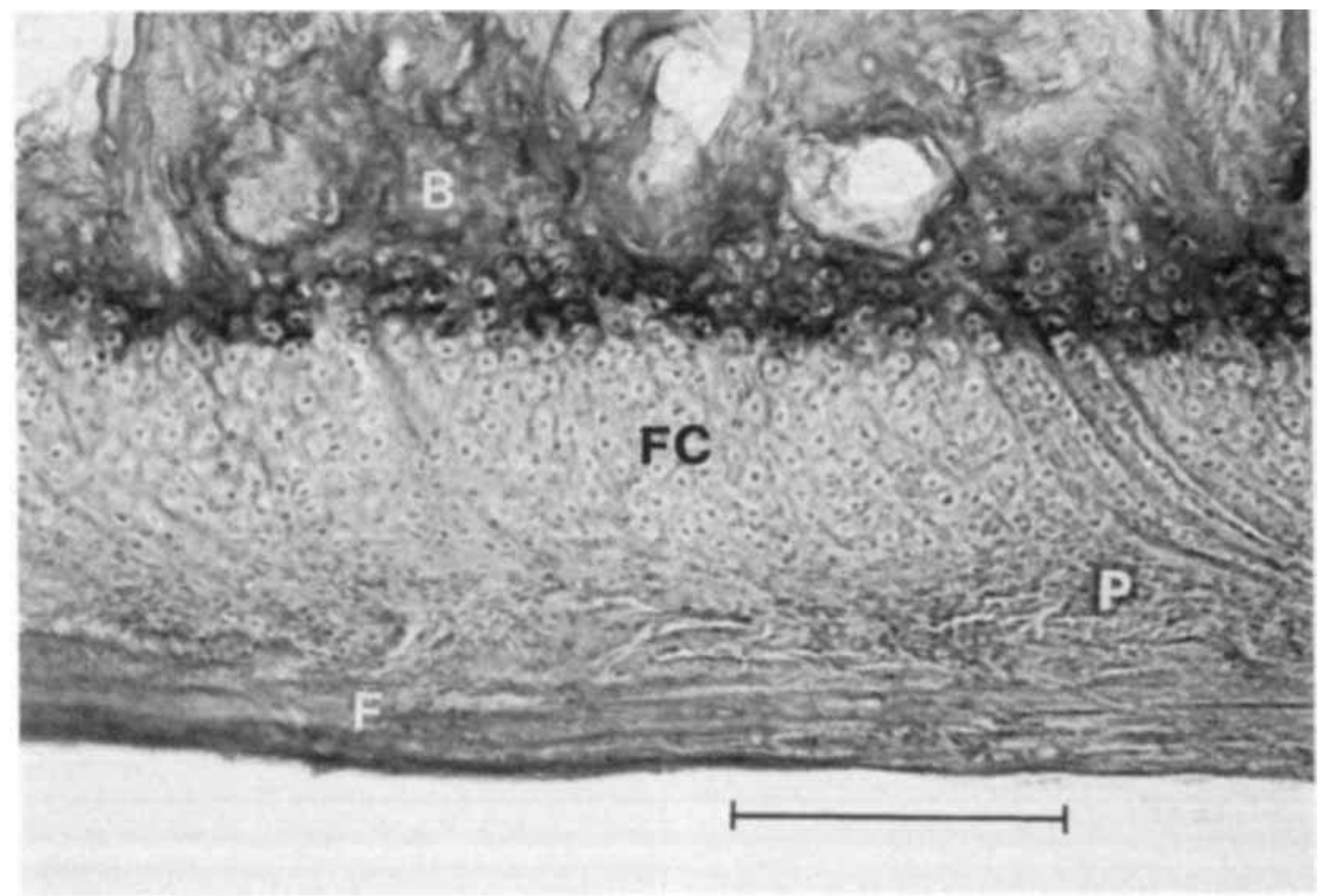

Fig. 10. Crest of articular eminence in an adolescent monkey. $\mathrm{H}$ and $\mathrm{E}$. Scale represents $200 \mu \mathrm{m}$. Interspersed among the chondrocytes ( $\mathrm{FC}$ ), note the fibers which run obliquely from the parallel-fibered articular layer to the underlying bone. Chondrocytes in the deepest layers appear to be surrounded by ossified matrix. $F=$ fibrous articular tissue; $\mathrm{P}=$ proliferative layer $; \mathrm{FC}=$ chondrocytes in fibrous matrix; $\mathrm{B}=$ bone of articular eminence. 
approximately $50 \mu \mathrm{m}$, whereas that on the eminence ranged from 100 to $150 \mu \mathrm{m}$. By comparison, mean thickness in the juvenile animals included in this study (18-30 months of age) ranged from 78 to $132 \mu \mathrm{m}$ in the fossa roof, depending on location of serial section, and from 128 to $140 \mu \mathrm{m}$ on the eminence crest. Description of the location and timing of cartilage cells is also in accord with that given by Zimmermann.

\section{Variation in articular-tissue thickness}

In its temporal component, the temporomandibular joint is without the articular cartilage which serves in other joints as a buffer against compressive stresses. Yet it has been demonstrated that forces are transmitted to the joint during mastication and incision (Hylander, 1979a; Hylander and Bays, 1979) and at levels which presumably necessitate morphological adaptation. Moffett et al. (1964) argued that the fibrous tissue which lines the articular surfaces of the temporal component serves to resist compressive loads resulting from function, and in so doing is transformed into fibrocartilage in heavily loaded areas. It also functions to minimizc shear stresses imposed by the translation of the condyle along the eminence under load. On this basis, Moffett and co-workers suggested that the increased thickness of articular tissue covering the eminence crest and posterior slope in relation to that seen in the fossa in humans is a reflection of greater functional stress on the eminence. However, the manner by which articular tissue thickens in response to functional stimuli is unclear. We have previously suggested (Carlson et al., 1978) that the thickening may be due to swelling brought about by increased water content, much as occurs in articular cartilage in regions undergoing greatest mechanical stress (Ekholm, 1955; Ekholm and Norback, 1951). The low rate of proliferative activity in the articular layer noted in radioautographic studies of the TMJ (Folke and Stallard, 1966, 1967; Kanouse et al., 1969; Joondeph, 1972; Blackwood, 1966) argues against thickening via increased mitotic activity.

\section{Variation in anteroposterior direction}

If topographical differences in articular-tissue thickness are representative of differential functional stress, then the variation in relative articular-layer thickness noted within and between maturational levels is presumably indicative of progressive alterations in function at the temporomandibular joint.
Viewed in this fashion, the data suggest that forces delivered to the joint become more anteriorly directed with age; i.e., in sagittal sections, the articular tissue in the fossa shows a trend of decreasing relative thickness, whereas that on the posterior slope and crest of the eminence undergoes a relative increase. In neonates and to a lesser extent in infants, the tissue in the fossa roof is roughly similar in thickness to that on the eminence, whereas in juveniles and at subsequent ages the tissue on the eminence becomes thicker than that in the fossa to an increasing degree.

Evidence of somewhat similar changes in relative thickness of the articular tissue with age have been documented for the condyle (Carlson et al., 1978). We suggested that alterations in the direction and degree of joint reaction forces with age might be correlated in part with age-related differences in morphology and function of the muscles of mastication. As maturation proceeds, the area of attachment of the anterior portion of temporalis becomes progressively more anteriorly located along the cranial vault. Also, with maturation the masseter unuscle supplants the more posteriorly oriented temporalis as the predominant jaw elevator during the closing phase of the chewing stroke (McNamara, 1974). These changes become apparent with the juveniles, and become increasingly more pronounced in adolescents and adults. It was argued that a likely outcome of these changes should be a more posteriorly directed muscle pull in young animals giving way to forces that are directed more anterosuperiorly as the anterior temporalis develops in mass and becomes relatively more forwardly positioned on the cranial vault, and as the masseter is more heavily utilized.

Further indications that forces at the TMJ may be directed more toward the posterior joint structures in young animals are provided by examination of certain features of temporal-joint-component anatomy. In monkeys, the morphology of the mandibular fossa and postglenoid spine contrasts greatly with that seen in humans. The mandibular fossa in monkeys is situated somewhat lateral to the braincase, not under it as in humans, and consists of a relatively thick cortex of lamellar bone, as opposed to the often paperthin fossa roof in the human basicranium (cf. Wright and Moffett, 1974; Sicher and DuBrul, 1975). Zimmermann (1971, Fig. 57) noted that considerable internal remodeling, 
as indicated by the presence of secondary osteons, was present in the fossa of some adult monkeys, giving it an appearance similar to the bone of the eminence. If functional forces are indeed transmitted to the fossa in growing monkeys, this may also be reflected in the presence at all ages of relatively thick articular tissue in the fossa compared to the eminence. In addition, the postglenoid spine, which is quite large in the monkey and is lined on its anterior surface with articular tissue, may be subject to forces transmitted by the condyle. Although the possibility of such contact is generally discounted in humans (cf. Sicher and DuBrul, 1975, p. 165), several workers have postulated that it may take place in monkeys. Zimmermann (1971) described gross resorption in corresponding areas on the postglenoid spine and posterior condylar surface on the dry skulls of several young monkeys, a finding which she interpreted as evidence of possible contact between the two structures. In addition,
Carlson et al. (1980) suggested that contact between the postglenoid spine and condyle may occur during agonistic displays. The data obtained from the samples studied here are fully consistent with these observations (Fig. 11). Thickness of articular tissue on the upper surface of the postglenoid spine exhibited trends most similar to those noted for the fossa roof-i.e., an overall increase in absolute thickness with age (Fig. 11a) which, when corrected for body size, reflects a steady decrease with age (Fig. 11b). Also, whereas relative articular tissue thickness in this area is as great or greater than that on the eminence in neonates and infants, it undergoes a steady decline with age (Fig. 11c). Relative articular-tissue thickness on the postglenoid spine and fossa roof combined drops from $51 \%$ in neonates to $30 \%$ in adults, whereas relative thickness on the posterior slope and eminence crest combined increases from $49 \%$ to $70 \%$. Therefore, several lines of evidence support the possibility of age-related changes

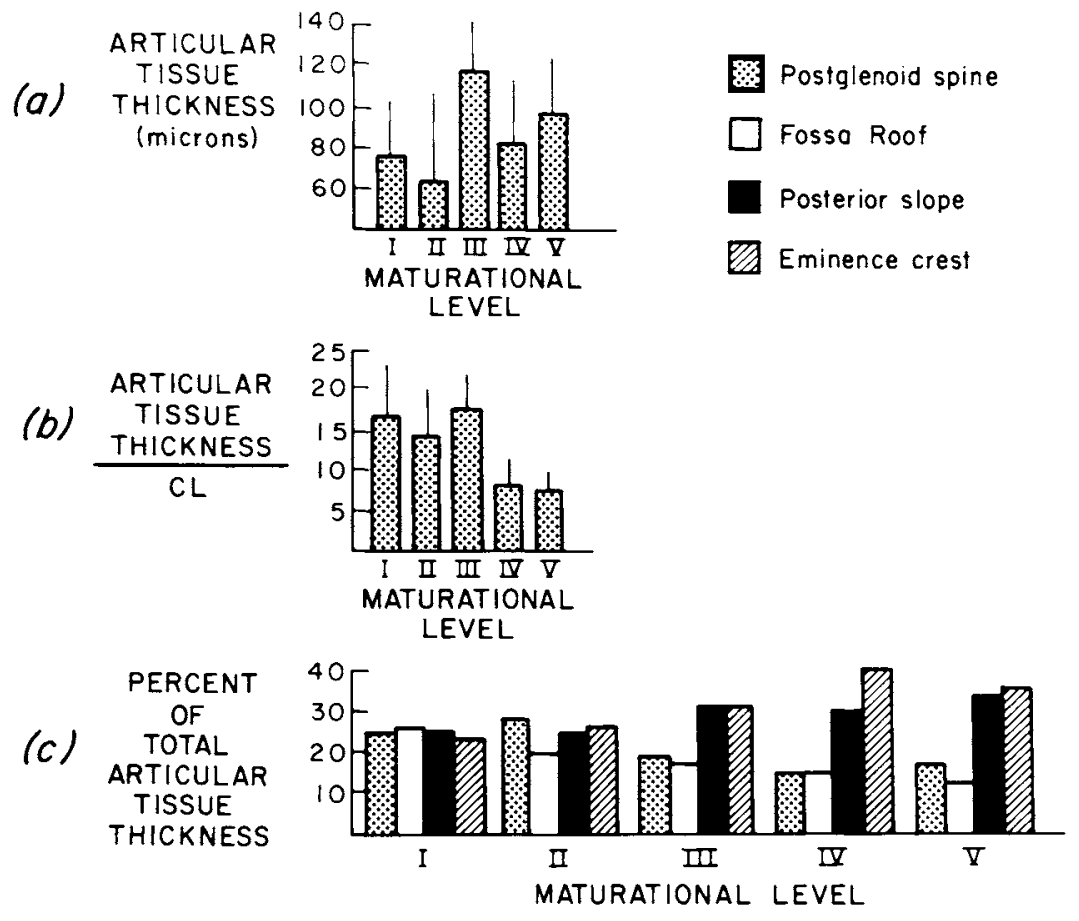

Fig. 11. Mean thickness of articular tissue on upper part of postglenoid spine. a) Mean thickness as a function of maturational level. b) Mean thickness divided by condylar length as a function of maturational level. c) Percent of total articular-tissue thickness represented by tissue on postglenoid spine, fossa roof, posterior slope, and crest of articular eminence as a function of maturational level. Thickness of articular tissue on postglenoid spine was measured in sections from the central part of the joint only. 
in direction and perhaps degree of forces at the temporomandibular joint.

\section{Variation in mediolateral direction}

Comparisons of articular-tissue thickness in the mediolateral direction showed mean tissue thickness to be consistently greater in more medial aspects of the joint than at its lateral aspect, a trend that was confirmed in the majority of animals for which serial sagittal sections were available. These results are seemingly in contradiction to those for human TMJs reported by Hansson and coworkers (Hansson and Nordstrom, 1977; Hansson et al., 1977), who found somewhat thicker soft-tissue layers laterally on the crest and posterior slope of the articular eminence. However, their sample lumped together adults of widely varying ages and also included several subadults, rendering comparisons with the data reported here difficult. It has been argued on the basis of indirect evidence that relatively greater stresses may be transmitted to the lateral aspect of the working-side TMJ than to the medial aspect during mastication (Hylander, 1979a; Hylander and Bays, 1979; Oberg et al., 1971; Hansson and Oberg, 1977). In particular, Hylander (1979a,b) suggested that this differential loading may result from the twisting of the working-side mandibular corpus along its long axis by opposing moments generated by the bite force and the muscles of mastication. Hylander argued that in the frontal plane a bite force with a transverse component will have a tendency to twist the working-side corpus by everting its alveolar process and inverting its lower border; the primary jaw elevators on the same side will exert an opposite twisting effect, tending to evert the lower border of the corpus and invert its alveolar process. As long as the twisting moment associated with the bite force does not completely counter the twisting moment associated with the working-side elevators, the lateral aspect of the articular surface of the working-side TMJ will then presumably be loaded to a greater extent than the medial aspect, although both under. go some stresses.

If articular tissue becomes relatively thicker in areas exposed to greater functional loading, then the thickness distribution in the mediolateral direction in monkeys may be interpreted as suggestive of somewhat greater loading medially. At the very least, the data reported here indicate that a differentially greater loading of the lateral part of the articular surface may not be nearly so pronounced in the temporomandibular joint of monkeys as in humans. The absolutely thinner articular-tissue thickness and generally more limited occurrence of cartilage cells in the deeper layers laterally in the monkey TMJ contrast with the morphology reported for humans (Hansson and Nordstrom, 1977; Hansson et al., 1977; Kopp, 1978). Consequently, based on the evidence presented here, it is possible that in adult monkeys the considerable twisting that apparently takes place in the working side mandibular corpus (Hylander, 1979b) may not be translated into differentially greater loading on the lateral aspect of the workingside TMJ.

The reasons for this disparity are not clear. However, the monkey differs from humans in a number of features of its oral apparatus and masticatory cycle which, when taken singly or in combination, may account for a somewhat altered pattern of loading at the monkey TMJ. For example, the orientation of the masticatory muscles, especially the temporalis, differs in the monkcy owing to altered relationships of face to neurocranium, thus potentially affecting the force distribution across the joint. In addition, the extent of the lateral jaw excursion during mastication is considerably less in monkeys than in humans (Byrd et al., 1978). The interplay of these factors may be crucial in determining the extent to which torsion occurs at the temporomandibular joint. Finally, whereas the long axis of the condylar head is directed in humans toward the foramen magnum at an angle with the frontal plane of from $0^{\circ}$ to $30^{\circ}$ (mean $=13^{\circ}$; Moffett, 1968), the condylar head in monkeys appears to lie almost parallel with the frontal plane or at a very small angle to it. The difference in relative positions of the lateral and medial poles of the condylar head inherent in such different orientations of the condyle may also contribute to an altered pattern of joint loading.

\section{Presence and significance of cartilage cells on the articular eminence}

Occurrence and probable source

Cells resembling chondrocytes were noted in the deeper layers of the fibrous articular tissue in animals at all maturational stages except neonates. These occurrences were limited primarily to the crest and posterior slope of the articular eminence. Moreover, their 
frequency and specificity of expression increased with age, beginning with sporadic, often discrete occurrences in infants, but often comprising a distinct layer of cells between the fibrous tissue and bone in juveniles, adolescents, and adults. Although this phenomenon has been noted by a number of workers, its description has given rise to a plethora of terms that are indicative of the uncertainty that surrounds its exact nature and origin. Tissue that appears to resemble that noted in the present study has been variously characterized as "fibrocartilage" (McNamara, 1972), "hyaline cartilage" (Zimmermann, 1971), and as "chondroid cells" (Kopp, 1978; Meikle, 1980). In addition, several researchers have described the presence of "hypertrophying chondrocytes" (Zimmermann, 1971; McNamara, 1972) or even a "hypertrophic layer" (Stöckli and Willert, 1971) in the deepest layers of the soft tissue on the eminence. Such contrasting terminology may also reflect the transitional nature of the tissue, bridging as it does a morphological and spatial gap between fibrous tissue and cartilage, or perhaps in its deepest mineralized layers, between cartilage and bone (cf. Beresford, 1981, p. 221).

The possible reasons for the presence of such a "cartilaginous" tissue on a bone which forms intramembranously have been little discussed for the TMJ. Both McNamara (1972) and Zimmermann (1971) attributed the "cartilage cells" to a changed functional pattern during maturation. Meikle (1980) suggested that cartilagelike cells in the articular layers of the TMJ in middle-aged and elderly humans arise by differentiation from articular layer fibroblasts in response to biomechanical stimuli resulting from joint function. Certainly this viewpoint is consistent with increasing evidence that a variety of reversible (modulatory) or irreversible (metaplastic) transformations involving all types of connective-tissue cells can and do occur, either indirectly from undifferentiated or mesenchymal cells or directly from other cell types (cf. Hall, 1970, 1978, and Beresford, 1981, for good summaries). In the monkeys studied here, the zone of cartilage and the fibroustissue layer were usually separated by a thin zone of small, seemingly undifferentiated cells which Zimmermann (1971) has likened to a "perichondrium." Moreover, the possibility that the matrix in the deepest layers of the cartilage adjacent to bone may become mineralized (see Ingervall et al., 1976) sug- gests that some of the tissue subsumed under a variety of names may be a tissue intermediate between cartilage and bone, or a "chondroid bone" (Beresford, 1981). ${ }^{1}$

The transformation of fibrous tissue to cartilaginous tissue has been documented at a number of locations in the human body, and not all such occurrences can be reliably attributed to the influence of functional or biomechanical stiumuli (Beresford, 1981). However, the tissue noted on the articular eminence bears some similarity to the "adventitious cartilage" described at the articular surfaces of intramembranous skull bones in the chick (cf. Hall, 1968), whose proliferation is attributed to intermittent mechanical stress. Moreover, the pattern of development of such a tissue is consistent with that observed on the articular eminence. Hall (1968, p. 803) noted that with the cessation of growth, the "adventitious cartilage" is "functionally replaced by a fibrocartilage and anatomically by bone"-an observation that is paralleled by the reduced presence or even the absence of a cartilage "layer" in older adults (see also Zimmermann, 1971) and the appearance in adults of scattered chondrocytes in the fibrous articular tissue. For the human TMJ, Moffett and co-workers (1964; see also Moffett, 1980) suggested that the articular eminence grows and remodels by a mineralization of the articular tissue and its subsequent replacement by lamellar bone. If so, the presence of a cartilage layer, possibly underlain by a mineralized layer of "chondroid bone," in certain areas of the articular surface of growing monkeys may reflect areas of strengthening and thickening of the bony cortex in response to biomechanical stimuli. In fact, Enlow (1975, p. 370) has noted that "chondroid bone" seems to be found in areas where rapid growth is taking place.

The supposition that the cartilage cells on the eminence in growing monkeys arise as a result of the action of biomechanical factors is supported by other, albeit circumstantial, evidence. For example, it is perhaps signifi-

\footnotetext{
${ }^{1}$ Beresford (1981, pp. 4,8) describes chondroid bone as having "functioning chondrocytes in a collagenous, but well mineralized matrix." He goes on to state that such a tissue usually occurs at the boundaries of a bone and has a "potentially major role in the skeleton's biomechanical relations with other tissues." Although nothing is known of the vitality of the chondrocytes in these deep layers, Ingervall et al. (1976, p. 137, Fig. 5 ) described the microradiographic appearance of the calcified car tilage on the eminence as "less radiopaque than bone" in a 14.5 . year-old-human and as "highly mineralized" in a 19.5-year-old specimen.
} 


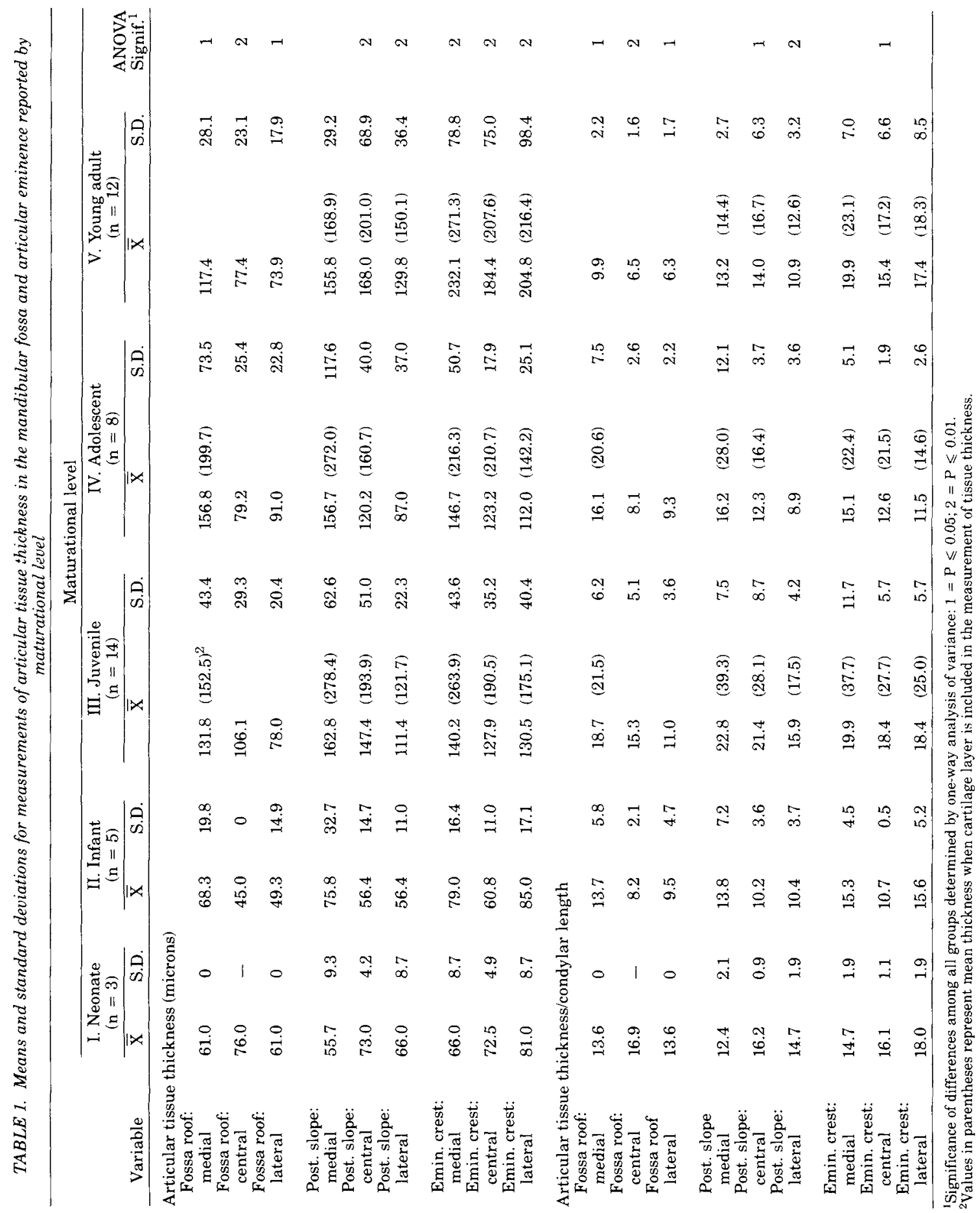


cant that cartilage cells were not observed in neonate animals and only sporadically in infants, both of which had presumably undergone little cumulative biomechanical stress, and that cartilage cells become considerably more obvious and more numerous in animals at later maturational levels. Moreover, the cartilage cell layer is most pronounced and thickest in juvenile animals, which also show the greatest articular-tissue thickness when corrected for condylar length (Tables 1, 2; Fig. 4). In addition, cartilage cells were noted repeatedly in those regions of the articular surface (primarily crest and posterior slope of the articular eminence) which are presumed on other grounds to be loaded during function. By contrast, even though a proliferative layer is sometimes noted deep to the articular tissue in the fossa roof, cartilage cells were almost never observed there, nor on the far anterior slope of the eminence. The existence of such tissue in humans during growth is disputed (Wright and Moffett, 1974; Thilander et al., 1976), although a somewhat similar phenomenon has been described in older adults (Meikle, 1980). However, the re- duced presence or complete absence of cartilage cells in growing humans compared to monkeys is consistent with a functional etiology for such cells, given the likelihood of greater reaction forces at the monkey TMJ (Carlson et al., 1980).

\section{Distribution of cartilage cells}

More importantly, the distribution of cartilage cells on the eminence roughly parallels that of the greatest thickness of articular tissue. Cartilage cells were observed on the eminence crest from medial to lateral (although on occasion, not medially) and extended back up the posterior slope in central and especially more medial sections, a fact noted also by Zimmermann (1971). Relative thickness in the coronal plane for each maturational level (Table 3) is as follows: 1) greatest medially or centrally in the fossa roof of all five age groups; 2) greatest centrally or medially on the posterior slope of the eminence in four of five age groups; 3 ) greatest laterally on the eminence crest in four of five age groups. Thus, the region of maximum relative articular-tissue thickness

TABLE 2. One-way analysis of variance of absolute and relative articular tissue thickness between maturational levels

\begin{tabular}{|c|c|c|c|c|c|c|c|c|c|c|}
\hline \multirow[b]{2}{*}{ Variable } & \multicolumn{10}{|c|}{ Maturational level pairs } \\
\hline & I-II & I-III & I-IV & $\mathrm{I}-\mathrm{V}$ & $\underline{\text { II-III }}$ & II-IV & $\mathrm{II}-\mathrm{V}$ & III-IV & III-V & IV-V \\
\hline \multicolumn{11}{|c|}{ Articular tissue thickness } \\
\hline Fossa roof: medial & & $*$ & $* *$ & & $*$ & $* *$ & & & & \\
\hline Fossa roof: central & & & & & $* *$ & $*$ & $*$ & $*$ & $*$ & \\
\hline Fossa roof: lateral & & & & & $*$ & $* *$ & & & & \\
\hline Post. slope: medial & & * & $*$ & $*$ & $*$ & & & & & \\
\hline Post. slope: central & & & & $*$ & $* *$ & $*$ & $* *$ & & & \\
\hline Post slope: lateral & & $*$ & & $* *$ & $* *$ & & $* *$ & & & $* *$ \\
\hline Emin. crest: medial & & $*$ & $*$ & $* *$ & $*$ & $*$ & $* *$ & & $* *$ & $*$ \\
\hline Emin. crest: central & & & & $* *$ & $* *$ & $*$ & $* *$ & & $* *$ & $\star$ \\
\hline Emin. crest: lateral & & & & $* *$ & & & $* *$ & & $* *$ & $* *$ \\
\hline \multicolumn{11}{|c|}{ Articular tissue thickness/condylar length } \\
\hline Fossa roof: medial & & & & & & & & & $* *$ & \\
\hline Fossa roof: central & & & $*$ & $*$ & $* *$ & & & $* *$ & $* *$ & \\
\hline Fossa roof: lateral & & & & $* *$ & & & & & $* *$ & \\
\hline Post. slope: medial & & $*$ & & & & & & & $*$ & \\
\hline Post. slope: central & & & & & $* *$ & & & $*$ & $*$ & \\
\hline Post. slope: lateral & & & $*$ & & $* *$ & & & $* *$ & $* *$ & \\
\hline \multicolumn{11}{|l|}{ Emin. crest: medial } \\
\hline Emin. crest: central & & & & & $* *$ & & & $*$ & & \\
\hline Emin. crest: lateral & & & & & & & & $*$ & & \\
\hline
\end{tabular}

${ }^{*} \mathrm{P} \leqslant 0.05$.

** $\mathrm{P} \leqslant 0.01$. 


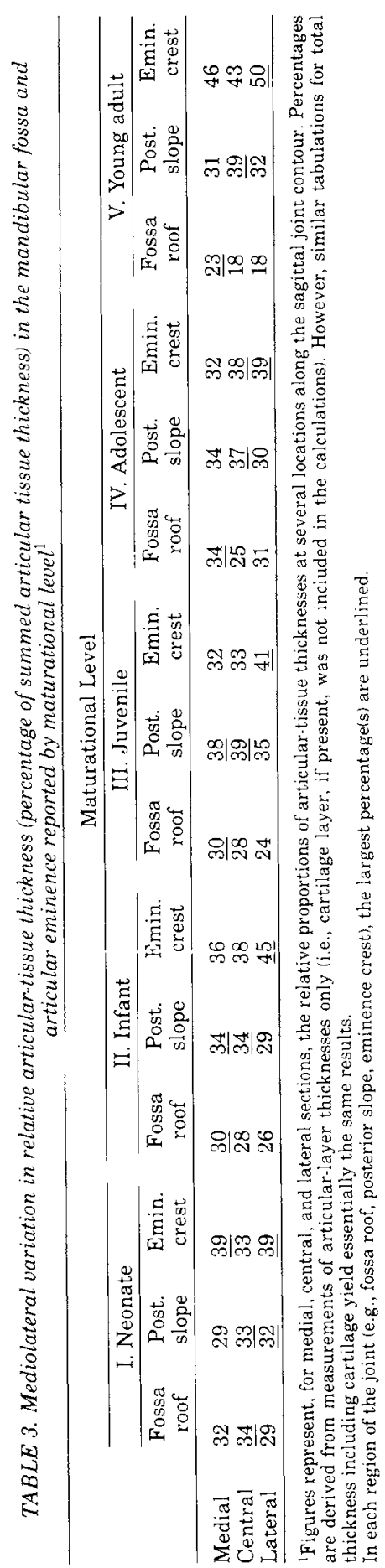

is located progressively more anteriorly as one moves from medial to lateral parts of the joint surface.

Mongini (1972) described a similar pattern of bony remodeling in the human mandibular condyle. Mongini noted that, whereas anteriorly flattened cross sections were the rule in the lateral parts of the condylar head, a more superiorly oriented flattening predominated in central and medial sections. In addition, though there was considerable evidence of remodeling all across the joint surface anteriorly, there was a tendency for the incidence of remodeling to increase from lateral to medial in the posterior one third of the joint. Similarly, Zimmermann (1971, Figs. 23, 24) noted that the articular disk, which appears compressed to a similar degree from lateral to medial in a frontal section through the anterior part of the joint, is "wedge-shaped" in a frontal section through the posterior part of the joint owing to differentially greater compression toward the medial aspect. Considered together, these observations suggest that the region of greatest functional stresses is located more posteriorly in medial and perhaps central parts of the joint than it is in lateral parts of the joint. This pattern of relative articular-tissue thickness characterizes virtually every maturational level, with the possible exception of the young adults. Although the position(s) of the condyle during the application of maximum joint-reaction force is not known, these forces are demonstrably greater at the balancing-side condyle in monkeys (Hylander, 1979a) than at the working-side joint. It is possible that the similar topographical variation in maximum articular-tissue thickness and in presence of cartilage cells may reflect the position of the balancing-side condyle during the transmission of maximum force to the articular eminence. Under such circumstances, the bulk of the reaction force would be delivered at some point during the simultaneous translation and rotation of the condyle back up into the fossa, with the medial pole of the condyle (which had rotated through a smaller arc during the opening sequence than had the lateral pole) becoming reestablished in the fossa (along the posterior slope) in advance of the lateral pole.

\section{CONCLUSIONS}

This study provides qualitative and quantitative documentation of microanatomical changes in the temporal component of the temporomandibular joint during growth of 
the rhesus monkey (Macaca mulatta). Exam ination of topographical variation in articular-tissue thickness with age demonstrates a trend of steadily decreasing relative thickness in the roof of the mandibular fossa and a relative increase in thickness on the posterior slope and crest of the articular eminence. These results parallel those obtained for the mandibular condyle and are best interpreted to indicate that forces delivered to the joint become more anteriorly directed with age. In addition, cells resembling chondrocytes are noted, often as a layer, on the posterior slope and crest of the eminence between the fibrous articular tissue and the underlying bone. This "cartilage" layer, first observed in juvenile monkeys but becoming more prominent with age, is probably the result of modulation of fibroblasts to chondroblasts in the deeper layers of the articular zone in response to biomechanical stimuli, and as such further reflects the more anterior orientation of joint forces in animals at older maturational levels. Moreover, the relatively greater articular-tissue thickness in the mandibular fossa roof and anterior surface of the postglenoid spine in neonate and infant monkeys, coupled with morphological differences with the analogous structures in humans, makes it likely that some forces are transmitted to these parts of the temporomandibular joint in monkeys. Articular-tissue thickness is absolutely greater medially than laterally in all age groups, although relative thickness is greatest laterally on the eminence crest at most age levels. All in all, however, the marked variation in articular-and cartilagelayer thickness cited in humans as evidence of differentially greater loading in the lateral aspect of the joint does not appear so pronounced in the monkey TMJ.

\section{ACKNOWLEDGMENTS}

This study was supported by NIH research grants DE 03610 and DE 05232, and by NIDR National Research Service Award DE05279. We gratefully acknowledge the technical assistance of Mr. John Beckerman, Mr. William Brudon, and Ms. Teryl Schessler.

\section{LITERATURE CITED}

Beresford, W.A. 1981 Chondroid Bone, Secondary Cartilage and Metaplasia. Urban and Schwarzenberg, Baltimore.

Blackwood, H.J.J. 1966 Growth of the mandibular condyle of the rat studied with tritiated thymidine. Arch. Oral Biol., 11:493-500.

Byrd, K.E., D.J. Milberg, and E.S. Luschei 1978 Human and macaque mastication: A quantitative study. J. Dent. Res., 57:834-843.

Carlson, D.S., J.A. McNamara, Jr., and D.H. Jaul 1978 Histological analysis of the growth of the mandibular condyle in the rhesus monkey (Macaca mulatta). Am. J. Anat., 151: 103-118.

Carlson, D.S., J.A. McNamara Jr., L.W. Graber, and D.H. Hoffman 1980 Experimental studies of the growth and adaptation of the temporomandibular joint. In: Current Concepts in Oral Surgery W.B. Irby, ed. C.V. Mosby, St. Louis, pp. 28-81.

Ekholm, R. 1955 Nutrition of articular cartilage. Acta Anat., 24:329-338.

Ekholm, R., and B. Norback 1951 Relation between articular changes and function. Acta Orthop. Scand., 21:81-98.

Elgoyhen, J.C., M.L. Riolo, L.W. Graber, R.E. Moyers, and J.A. MeNamara Jr. 1972 Craniofacial growth in juvenile Macaca mulatta: A cephalometric study. Am. J. Phys. Anthropol., 36:369-376.

Enlow, D.H. 1975 Handbook of Facial Growth. Saunders, Philadelphia.

Folke, L.E.A., and R.E. Stallard 1966 Condylar adapta tion to a change in intermaxillary relationship. J. Periodont. Res., 1:79-89.

Folke, L.E.A., and R.E. Stallard 1967 Cellular kinetics within the mandibular joint. Acta Odont. Scand., 25:469-489.

Granados, J.I. 1979 The influence of the loss of teeth and attrition on the articular eminence. J. Prosthet. Dent., 42:78-85.

Hall, B.K. 1968 The fate of adventitious and embryonic articular cartilage in the skull of the common fowl, Gallus domesticus (Aves: Phasianidae). Aust. J. Zool., 16:795-805

Hall, B.K. 1970 Cellular differentiation in skeletal tissues. Biol. Rev., 45:455-484

Hall, B.K. 1978 Developmental and Cellular Skeletal Biology. Academic Press, New York.

Hansson, T., and B. Nordstrom 1977 Thickness of the soft tissue layers and articular disk in temporomandibular joints with deviations in form. Acta Odont. Scand., 35:281-288.

Hansson, T., and T. Oberg 1977 Arthrosis and deviation in form in the temporomandibular joint. A macroscopic study on a human autopsy material. Acta Odont. Scand., 35:167-174.

Hansson, T., T. Oberg, G.E. Carlsson, and S. Kopp 1977 Thickness of the soft tissue layers and the articular disk in the temporomandibular joint. Acta Odont. Scand., 35:77-84

Hiniker, J.J., and S.P. Ramfjord 1966 Anterior displacement of the mandible in adult rhesus monkeys. I. Prosthet. Dent., 16:503-512.

Hinton, R.J. 1981 Changes in articular eminence morphology with dental function. Am. J. Phys. Anthropol., $54: 439-455$

Hurme, V.O., and G. van Wagenen 1953 Basic data on the emergence of deciduous teeth in the monkey ( $\mathrm{Ma}$ caca mulatta). Proc. Am. Phil. Soc., 97:291-315.

Hurme, V.O., and G. van Wagenen 1961 Basic data on the emergence of permanent teeth in the rhesus monkey (Macaca mulatta). Proc. Am. Phil. Soc., 105:105140.

Hylander, W.L. 1979a An experimental analysis of temporomandibular joint reaction forces in macaques. Am. J. Phys. Anthropol., 51:433-456.

Hylander, W.L. 1979b Mandibular function in Galago crassicaudatus and Macaca fascicularis: An in vivo approach to stress analysis of the mandible. J. Morphol., 159:253-296.

Hylander, W.L. and R. Bays 1979 An in vivo strain 
gauge analysis of squamosal-dentary joint reaction force during mastication and incision in Macaca mulatta and Macaca fascicularis. Arch. Oral Biol., 24:689697.

Ingervall, B., G.E. Carlsson, and B. Thilander 1976 Postnatal development of the human temporomandibular joint. II. A microradiographic study. Acta Odont. Scand., 34:133-139.

Joondeph, D.R. 1972 An autoradiographic study of the temporomandibular articulation in the growing Saimiri scuireus monkey. Am. J. Orthodont., 62:272-286.

Kanouse, M.C., S.P. Ramfjord, and C.E. Nasjleti 1969 Condylar growth in rhesus monkeys. J. Dent. Res., 48:1171-1176.

Kopp, S. 1978 Topographical distribution of sulfated glycosaminoglycans in the surface layers of the human temporomandibular joint. J. Oral Pathol., 7:283-294.

McNamara, J.A. Jr. 1972 Neuromuscular and Skeletal Adaptations to Altered Orofacial Function. Monograph No. 1, Craniofacial Growth Series, Center for Human Growth and Development, University of Michigan, Ann Arbor.

McNamara, J.A. Jr. 1974 An electromyographic study of mastication in the rhesus monkey (Macaca mulatta). Arch. Oral Biol., 19:821-823.

Meikle, M.C. 1980 Remodeling. In: The Temporomandibular Joint: A Biological Basis for Clinical Practice. B.G. Sarnat and D.M. Laskin, eds. Charles C. Thomas, Springfield, Illinois, pp. 205-226.

Moffett, B.C. 1968 The temporomandibular joint. In: Complete Denture Prosthodontics. J.J. Sharry, ed., 2nd Ed. McGraw-Hill, New York, pp. 56-104.

Moffett, B.C. 1980 Clinical biology of the craniofacial articulations. Am. Equil. Soc. Comp., 15:420-431

Moffett, B.C., L.C. Johnson, J.B. McCabe, and H.C. As kew 1964 Articular remodeling in the adult temporomandibular joint. Am. J. Anat., 115:119-142.

Mongini, F. 1972 Remodeling of the mandibular condyle in the adult and its relationship to the condition of the dental arches. Acta Anat., 82:437-453.

Oberg, T., G.E. Carlsson, and C.M. Fajers 1971 The temporomandibular joint. A morphologic study on a human autopsy material. Acta Odont. Scand., 29:349 384.

Seward, F.S. 1976 Tooth attrition and the temporoman dibular joint. Angle Orthodont., 46:162-170.

Sicher, H., and E.L. DuBrul 1975 Oral Anatomy, 6th Ed. C.V. Mosby, St. Louis.

Stöckli, P.W. and H.G. Willert 1971 Tissue reactions in the temporomandibular joint resulting from anterior displacement of the mandible in the monkey. Am. J. Orthodont., 60:142-155.

Thilander, B., G.E. Carlsson, and B. Ingervall 1976 Postnatal development of the human temporomandibular joint. I. A histologic study. Acta Odont. Scand., 34:117126

Wright, D.M. and B.C. Moffett 1974 The postnatal development of the human temporomandibular joint. Am. J. Anat., 141:235-250.

Zielinski, D.E. 1965 A study of the Normal Anatomy of the Masticatory Apparatus of Macaca mulatta. Unpublished Master's Thesis, Loyola University, Chicago.

Zimmermann, H.I. 1971 The Normal Growth and Remodeling of the Temporomandibular Joint of Macaca mulatta. Unpublished Master's Thesis, University of Washington, Seattle. 